\title{
Reliability allocation of rotary ultrasonic vibration- assisted EDM machine tool based on maximum entropy ordered weighted average and constraint under the index of overall cost
}

\author{
Minggang Xu \\ North China University of Technology \\ Hao Fu (D987765449@qq.com ) \\ North China University of Technology \\ Wang Tian \\ North China University of Technology \\ Binbin Lyu \\ North China University of Technology \\ Zihao Jiang \\ North China University of Technology \\ Baosheng Guan \\ North China University of Technology
}

\section{Research Article}

Keywords: the maximum entropy ordered weighted average, rotary ultrasonic vibration-assisted EDM, predict maintenance cost, corrective maintenance cost, maintenance cycle, reliability

Posted Date: May 7th, 2021

DOl: https://doi.org/10.21203/rs.3.rs-459032/v1

License: (c) (i) This work is licensed under a Creative Commons Attribution 4.0 International License. Read Full License 
Reliability allocation of rotary ultrasonic vibration-assisted EDM machine tool based on maximum entropy ordered weighted average and constraint under the index of overall cost

\author{
Minggang Xu, Hao Fu*,Wang Tian, Binbin Lyu, Zihao Jiang, Baosheng Guan \\ School of Mechanical and Materials Engineering, North China University of \\ Technology, Beijing, China
}

\begin{abstract}
Rotary ultrasonic vibration-assisted EDM is a composite machining method which uses EDM technology to process metal surface and adds rotation and ultrasonic vibration. In this paper, the failure rate of each module of the rotary ultrasonic vibration-assisted EDM machine tool can be accurately predicted by the maximum entropy ordered weighted average algorithm so that the corrected maintenance cost can be predicted. And effective control of preventive maintenance costs can be achieved by selecting the best maintenance times under the premise of reliability. The results showed that the reliability of rotary ultrasonic vibration-assisted EDM machine tool is smoother at nonfixed maintenance intervals by varying the maintenance interval according to the comparison between non-fixed and fixed maintenance cycle. The cost of corrective maintenance can be reduced by varying the measurement to achieve cost optimization in the context of reliability with an optimum number of maintenance cycles and reliability.
\end{abstract}

Keywords the maximum entropy ordered weighted average; rotary ultrasonic vibration-assisted EDM ; predict maintenance cost; corrective maintenance cost; maintenance cycle; reliability

\title{
1 Introduction
}

The principle of electrical discharge machining [1] is to use the electro-corrosion phenomenon generated by the pulse discharge between the two poles to process the material, which belongs tothe category of electro-physical machining academically. It has a wide processing range (Suitable for a wide range of difficult-to-process materials) and the machining process is non-contact and free of significant mechanical force. It is suitable for precision micro and the precision to the micron level, as well as being highly degree of automated and intelligent to make the processed workpiece profiling reality and other advantages. However, there are also limitations that the production efficiency is lower than such as cutting, electrode losses during machining, which affects the forming accuracy and the minimum corner radius during machining,

\footnotetext{
*Hao Fu

School of Mechanical and Materials Engineering, North China University of Technology, Beijing, China

No. 5, Jinyuanzhuang Road, Shijingshan District, Beijing

987765449@qq.com
} 
as well as the impact on the surrounding material structure during electrical discharge erosion. In order to overcome this limitation, the rotary ultrasonic vibration- assisted EDM technology [2-3] has been studied based on various theories. Dong Yinghuai and Song Jianbao etc. [4] have proposed a non-contact power supply technology using the principle of electromagnetic induction to solve the concentration of sparks and abnormal arcs generated by the use of carbon brushes and circulating power supply, and an ultrasonic vibration-assisted EDM machine was also be designed. Yan Wang and Zhiqiang Liu etc. [5] have found that by adjusting the performance of ultrasonic vibration energy and EDM energy, the quality of the machined surface can be altered. Hirao A and Gotoh H etc. [6] have studied the influence of different amplitudes on the characteristics of EDM by using the auxiliary ultrasonic vibration method of the tool electrode. Kumar S and Grover S etc. [7] have established the performance index system model of ultrasonic vibration-assisted EDM by using graph theory and obtained the performance index of ultrasonic-assisted EDM from matrix model and digraph to understand the ability of influencing subjective factors. Lin YC and Chuang FP etc. [8] have used the combination of ultrasonic vibration and auxiliary magnetic force with EDM technology to overcome the bottleneck of processing large-area applications. Shervani-Tabar M T etc. [9] have studied the bubble generation and material removal rate through the influence of the simultaneous vibration of the tool and the workpiece on the hydrodynamic behavior of the liquid flow around the bubble. Reza Teimouri, Hamid Baseri etc. [10] have studied the influence of rotating magnetic field and ultrasonic vibration of the work piece on the performance of EDM process. and the results show that the magnetic field has a positive effect on MRI and SR.

The reliability distribution of the individual modules of the rotary ultrasonic vibration-assisted EDM machine is one of the most important factors that need to be considered when determining the overall reliability and competitiveness, and it is also an important analytical tool that can be used to improve the reliability of the system. In recent years, the rational distribution of system weights based on the maximum entropy ordered weighted average method has been applied in various fields. Under the premise of reliability, people have continuously researched new algorithms for the optimization of system costs to achieve cost savings. Cheng Q and H Wang etc. [11] have combined the fuzzy allocation method and the maximum entropy ordered weighted average to realize the reliable and flexible allocation of the CNC machine tool system. Maldonado $\mathrm{S}$ and J Merigó etc. [12] have redefined the soft-edge support vector machine (SVM) formula by introducing the ordered weighting (OWA) operator. The results show that this method has the best overall performance compared with the standard support vector machine. Chaji A etc. [13] have determined the maximum Bayesian entropy model of ordered incremental average (OWA) operation related weights and determined the analytical form of OWA weights through the Lagrangian multiplier method. Kabir G etc. [14] have used Bayesian linear regression and uncertainty analysis of the method of sequential weighted averaging for predicting water pipe failure. Yari $\mathrm{G}$ and Chaji etc.[15] have obtained the maximum Bayesian entropy of OWA operator weights and solved the new model with a specific Orness level based on the prior OWA vector. Ahn B S etc. [16] have studied the metric developed from the OWA method that can attach 
some semantics to the approximate weight and generate the weight by the maximum entropy method. S-Trean etc. [17] have studied the optimal solution of a class of constrained interval-valued optimization problems with path-independent curvilinear integral cost function control, and established the minimum criteria of the optimal solution through the constrained variable Lu optimal solution and global Lu optimal solution of PDE and PDI. Y Zhou, R Zhang, etc. [18] have adopted the system optimization maintenance cost as the objective function and optimized the system maintenance cycle through time and maintenance interval subject to the minimum system reliability constraints. Liu J and Chen Q etc. [19] have proposed a costconstrained optimization algorithm that considers the laser powder bed additive manufacturing process, which optimizes metal additive manufacturing parts under the condition of strictly limiting the manufacturing cost. R Cajzek and U Klanek etc. [20] have proposed a MINLP model for project schedule and cost optimization under resource and application constraints, and realize the optimization of the production process while resource-constrained scheduling. S Domínguez-Isidro etc. [21] have proposed a multi-mode differential local search coordination algorithm for solving the constrained numerical problems, which is suitable for local search operators that are fully coordinated in a limited search space.

The above research results showed that the theory under the maximum entropy ordered weighted average and total cost index has not been applied to rotary ultrasonic vibration-assisted EDM machine tools. In this paper, a design method of rotary ultrasonic vibration-assisted EDM machine tool based on maximum entropy ordered average and reliability allocation under the total cost constraint is proposed. It is to predict the reliability of the overall structure of the machine tool and achieve the purpose of cost optimization.

\section{Design of Rotary Ultrasonic Vibration-Assisted EDM Machine Tool}

\subsection{Structural design of ultrasonic vibration-assisted EDM}

The main task of the servo control of the rotary ultrasonic vibration-assisted EDM is ensuring stable and effective electrical discharge between the tool electrode and the workpiece. The rotary ultrasonic vibration-assisted EDM control system adopts an open architecture mode of upper computer (PC industrial computer) + lower computer

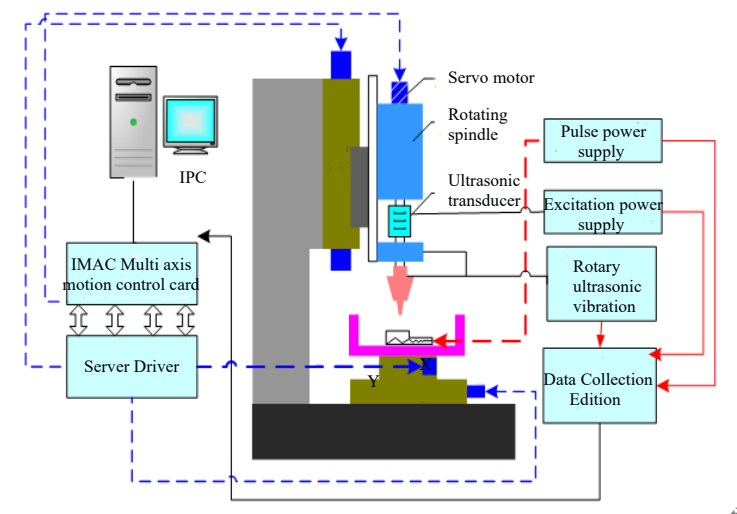

Fig.1 Schematic diagram of the control system of the rotary ultrasonic vibration-assisted EDM machine tool 
(IMAC400 motion controller). The two are connected through the Ethernet bus to realize information transmission. The upper computer sends instructions to the IMAC400 motion control card, which drives the ball screw through the servo motor to drive the tool electrode to move. The composition of the control system of the EDM machine tool is shown in Fig.1.

\subsection{Structural Design of Rotary Ultrasonic vibration-assisted EDM Machine Tool}

Fig. 2 shows the 3D modeling diagram of the self-developed rotary ultrasonic vibrationassisted EDM machine tool. The main body of the platform is an X-Y-Z three-axis workbench. The $\mathrm{X}$ and $\mathrm{Y}$ axes are placed in a cross shape and the three linear axes are

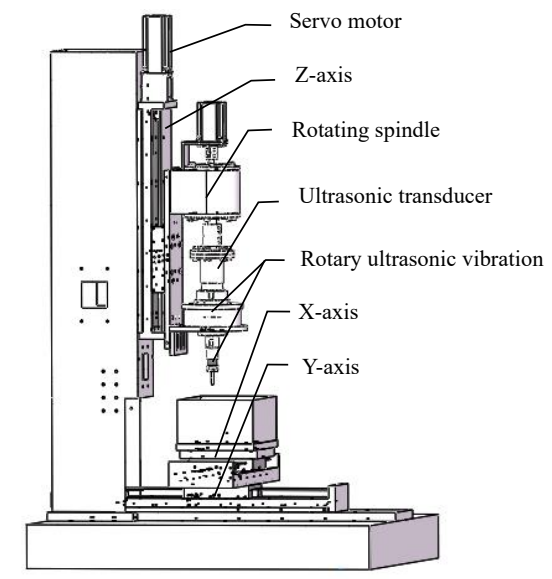

Fig.2 3D modeling of rotary ultrasonic vibration-assisted EDM machine tool

all driven by guide screws and servo motors. A working fluid tank and a workpiece clamping device are installed on the $\mathrm{X}$-axis sliding plate. The $\mathrm{Z}$ axis stands vertically on the processing platform and drives the rotating spindle to move in the vertical direction. The rotating ultrasonic spindle is composed of a motor, an ultrasonic bracket, a rotary-ultrasonic vibration device, and a tool electrode. The rotary ultrasonic vibration-assisted EDM machine tool is shown in Fig.3.

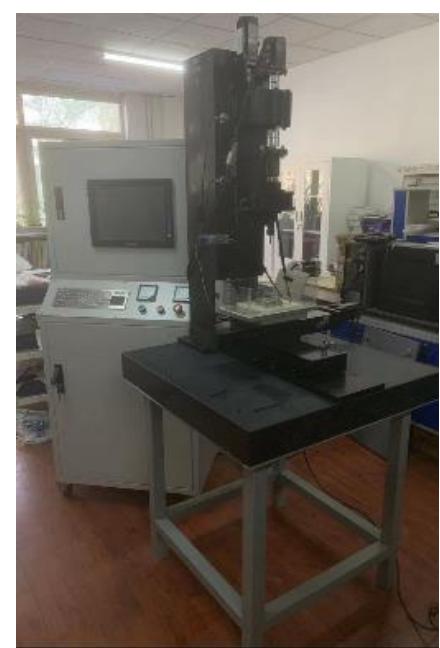

Fig.3 Rotary ultrasonic vibration-assisted EDM machine tool

The rotary ultrasonic vibration-assisted EDM machine tool includes five modules: $\mathrm{X}-\mathrm{Y}$ axis motion system, $\mathrm{Z}$ axis motion system, spindle rotation system, ultrasonic 
vibration system and servo control system. The hardware of the servo control system mainly includes industrial machine, motion control card, servo motor, encoder, pulse power supply, ultrasonic vibration generator, etc. In this paper, the five modules are analyzed based on the ordered average of maximum entropy and the reliability allocation under the total cost constraint. In order to achieve the overall structural reliability and cost optimization of the machine tool.

\section{Analysis of the failure rate of each module of the system based on the orderly weighted average of maximum entropy}

The complexity (I), technical level (S), working time (P) and working environment (E) of each module of the rotary ultrasonic vibration assisted EDM machine tool was weighted based on the maximum entropy ordered weighted average method, and the failure rate of each module can be calculated under different measures.

Firstly, the overall structure of the rotary ultrasonic-vibration-assisted EDM machine tool is evaluated to determine the reliability $(\mathrm{R})$ and the working time $(\mathrm{T})$ of operation and to calculate the total failure rate of the system.

$$
\lambda_{s}=\frac{-\ln R}{T}
$$

Where :

$R$-Reliability of Rotary Ultrasonic vibration-assisted EDM Machine Tool ;

$\mathrm{T}$-Working hours of rotary ultrasonic vibration-assisted EDM machine tool;

$\lambda_{s}$ - Total failure rate of rotary ultrasonic vibration-assisted EDM machine tool.

The assigned value $w_{\mathrm{k}}$ of each module is :

$$
w_{k}^{\prime}=r_{I k} \cdot w_{1}+r_{S k} \cdot w_{2}+r_{P k} \cdot w_{3}+r_{E k} \cdot w_{4}
$$

Where :

$r_{I k} 、 r_{S k}, r_{P k}, r_{E k}$-represent the ISPE value of each module;

$w_{1} 、 w_{2} 、 w_{3} 、 w_{4}$ - ISPE assigned weight.

The complexity $\mathrm{C}_{\mathrm{k}}$ of each module is :

$$
C_{k}^{\prime}=\frac{w_{k}{ }^{\prime}}{\sum_{i=1}^{n} w_{i}^{\prime}},(k=1,2 L, 5)
$$

The failure rate $\lambda_{k}$ of each module is:

$$
\lambda_{k}=C_{k}^{\prime} \lambda_{s},(k=1,2 L, 5)
$$

The Orness measurement level is used to obtain the weight of the OWA operator based on the maximum entropy method, that is, the weight vector of the MEOWA operator. The Lagrangian algorithm is used to solve the OWA polynomial to obtain the analysis of the weight function as [22-23] :

(a) when $\alpha=0, w=[0,0, \ldots 1]^{T}$, when $\alpha=1, w=[1,0, \ldots 0]^{T}$

(b) when $n=2, w_{1}=\alpha, w_{2}=1-\alpha$

(c) when $n \gg 3,0<\alpha<1$, then

$$
\begin{aligned}
& w_{1} \cdot\left[(n-1) \cdot \alpha+1-n w_{1}\right]^{n} \\
= & {[(n-1) \cdot \alpha]^{n-1} \cdot\left[((n-1) \cdot \alpha-n) \cdot w_{1}+1\right] } \\
& w_{i}=\left(w_{1}^{n-i} w_{n}^{i-1}\right)^{\frac{1}{n-1}}
\end{aligned}
$$




$$
w_{n}=\frac{((n-1) \cdot \alpha-n) w_{1}+1}{(n-1) \cdot \alpha+1-n w_{1}}
$$

Where :

$w$-Weight vector;

$\alpha$-measure;

$n$-Number of attributes.

Calculate different reliability distribution values to obtain different optimal weight vectors according to the selection of different measures. Table. 1 selects the measured values $(\alpha=0.5,0.6,0.7,0.8,0.9,1.0)$ for calculation. The measured values from low to high represent the technician's optimism about the reliability of the machine tool, taking $\mathrm{n}=4$ and calculating the optimal weight vector according to equations (5)-(7).

Table. 1 MEOWA weight vectors under different measures

\begin{tabular}{lcccc}
\hline & $w_{1}$ & $w_{2}$ & $w_{3}$ & $w_{4}$ \\
\hline$\alpha=0.5$ & 0.25000 & 0.25000 & 0.25000 & 0.25000 \\
$\alpha=0.6$ & 0.41666 & 0.23334 & 0.13086 & 0.07355 \\
$\alpha=0.7$ & 0.49381 & 0.23731 & 0.11377 & 0.05492 \\
$\alpha=0.8$ & 0.59647 & 0.25195 & 0.10645 & 0.04502 \\
$\alpha=0.9$ & 0.76410 & 0.18213 & 0.04346 & 0.01036 \\
$\alpha=1.0$ & 1.00000 & 0.00000 & 0.00000 & 0.00000 \\
\hline
\end{tabular}

The Delphi method is used to determine each module of the rotary ultrasonic vibration EDM machine tool according to the type of hardware of the servo control system and the screw type of the XYZ axis, the lead of the screw and the length of the main shaft, the speed of the ultrasonic vibration gear lever and the development method Complexity (I), technical level (S), working hours (P) and working environment (E). As shown in Table.2:

Table.2 ISPE value of each module

\begin{tabular}{lcccc}
\hline & $(\mathrm{I})$ & $(\mathrm{S})$ & $(\mathrm{P})$ & $(\mathrm{E})$ \\
\hline Servo control & 7 & 7 & 8 & 2 \\
X-Y -axis motion & 4 & 4 & 8 & 3 \\
Z-axis motion & 4 & 5 & 8 & 3 \\
Spindle rotation & 5 & 6 & 8 & 3 \\
Ultrasonic vibration & 6 & 7 & 8 & 3 \\
\hline
\end{tabular}

The reliability of the rotary ultrasonic vibration-assisted EDM machine tool is 0.875 , and the task time is $1000 \mathrm{~h}$. According to formula (1), the total failure rate of the system is:

$$
\lambda_{s}=\frac{-\ln 0.875}{1000}=1.3531 \times 10^{-4}
$$

The failure rate of each module (every $10^{5}$ hours) can be obtained according to formula (2)-(4), as shown in Table.3:

In Table 3, the data of the failure rate of each module under different measures are available, and the failure rate of each module is predicted under the continuous reliability, so as to achieve the analysis of the overall reliability of the machine tool. When $\alpha=0.5$, the total failure rate of each module of the rotary ultrasonic vibrationassisted EDM machine has the shortest time to occur, so the technician needs to be 
careful in his assessment.

Table.3 Failure rate of each module under different measures

\begin{tabular}{lrllrrr}
\hline & $\alpha=0.5$ & $\alpha=0.6$ & $\alpha=0.7$ & $\alpha=0.8$ & $\alpha=0.9$ & $\alpha=1.0$ \\
\hline Servo control & 1.51884 & 1.73408 & 1.77695 & 1.80723 & 1.89263 & 1.94733 \\
X-Y-axis & 1.20241 & 1.16759 & 1.15786 & 1.15053 & 1.12704 & 1.11276 \\
Z-axis & 1.26570 & 1.23803 & 1.22656 & 1.21670 & 1.17634 & 1.11270 \\
Spindle rotation & 1.39227 & 1.43426 & 1.43823 & 1.43955 & 1.43247 & 1.39095 \\
Ultrasonic vibration & 1.51884 & 1.63050 & 1.64990 & 1.66239 & 1.68860 & 1.66914 \\
\hline
\end{tabular}

\section{Reliability allocation of Revolving Ultrasonic Vibration-assisted EDM Machine Tool under Total Cost Index}

The lifetime of the rotary ultrasonic vibration-assisted EDM machine tool is a balance between the maintenance cost and reliability of multiple modules. All modules use the same preventive maintenance interval to avoid frequent machine downtime due to maintenance of a single module. Therefore, the optimization of the maintenance strategy requires a reasonable planning of the preventive maintenance interval of the system, predicting the cost of corrective maintenance based on different measures, and considering the maintenance cost and the reliability of the system throughout its life cycle [24].

\subsection{Mathematical Model of Cost and Reliability of Rotary Ultrasonic Vibration- Assisted EDM Machine Tool}

The goal of cost optimization is to determine the optimum $(\mathrm{N}, \mathrm{T})$ within a limited life span to optimize the system maintenance cost at the lowest reliability level of the system life, $\mathrm{N}$ is the number of preventive maintenance of the machine tool, and $\mathrm{T}=$ $\left\{\mathrm{T}_{\mathrm{P} 0}, \mathrm{~T}_{\mathrm{P} 1}, \ldots, \mathrm{T}_{\mathrm{Pk}}, \ldots, \mathrm{T}_{\mathrm{PN}}\right\}$ is the best maintenance interval. The maintenance cost of the machine tool includes $\mathrm{N}$ preventive maintenance (PM) and corrective maintenance $(\mathrm{CM})$. The interval between $\mathrm{N}$ preventive maintenance activities is not fixed. Corrective maintenance for faults occurring during each preventive maintenance interval. The number of corrective maintenance is related to the reliability of the multicomponent system.

The maintenance cost of the rotary ultrasonic vibration-assisted EDM machine tool is :

Where:

$$
c_{\text {total }}(\mathrm{N}, \mathrm{T})=N c_{p}+c_{e}
$$

$c_{\text {total }}(\mathrm{N}, \mathrm{T})$ - The total maintenance cost of the system over its limited lifetime;

$c_{p}$-Preventive maintenance cost of machine tools;

$c_{e}$ - Corrective maintenance cost.

Corrective maintenance cost is :

$$
c_{e}=\sum_{i=1}^{n} c_{i} h_{\text {itotal }}
$$

Where:

$c_{i}$ - Corrective maintenance cost of each module of the machine tool; 
$h_{\text {itotal }}$ - The failure time of the i-th module in its limited life.

Considering that the optimization of maintenance costs would lead to the reduction in machine reliability, the reliability of the machine tool can be used as the constraint for solving the model, and the maintenance strategy optimization model is obtained as:

Where:

$$
\begin{gathered}
c_{\text {total }}(\mathrm{N}, \mathrm{T})=N c_{p}+\sum_{i=1}^{n} c_{i} h_{\text {itotal }} \\
R_{k} \gg R_{\text {min }}
\end{gathered}
$$

$R_{k}$-Machine reliability;

$R_{\min }$-Machine reliability constraints.

The reliability of rotary ultrasonic vibration-assisted EDM machine tools mainly adopts Weibull distribution, which is applied to the description of the failure rate function and the modelling of the lifetime of each module of the machine. It is assumed that all components satisfy the Weibull distribution to simplify the calculation, namely:

$$
\lambda_{i}(t)=\frac{m_{i} t^{m_{i}-1}}{\mu_{i}^{m} i}
$$

Where:

$\lambda_{i}(t)$-Failure rate of the i-th module of the machine tool;

$m_{i}$-Shape parameter;

$\mu_{i}$ - Scale parameter.

Considering the influence of shape parameters and scale parameters on failure rate, a new model for the change in failure rate after preventive maintenance of equipment was developed. The function relationship of failure rate before and after maintenance as follows:

$$
\lambda_{i, k+1}(t)=b_{i, k} \lambda_{i, k}\left(t+\alpha_{i, k} \cdot T_{k}\right), 0<t<T_{k+1}
$$

Where:

$a_{i, k}$ - Life reduction factor of the i-th module during the k-th preventive maintenance;

$b_{i, k}$ - Risk increase factor of the $\mathrm{i}$-th module during the $\mathrm{k}$-th preventive maintenance.

In this recurrence relationship, the initial value of the equipment failure rate is updated to $b_{i, k}\left(\alpha_{i, k}, T_{k}\right)$ after the maintenance operation. To simplify the calculation, the age reduction factor and the risk rate increase factor remain unchanged as follows:

$$
\begin{aligned}
& a_{i, 0}=a_{i, 1}=\cdots=a_{i, N}<1 \\
& b_{i, 0}=b_{i, 1}=\cdots=b_{i, N}>1
\end{aligned}
$$

The failure rate of the $i$-th module of the machine tool after $\mathrm{K}$ preventive maintenance cycles is:

$$
\lambda_{i, k+1}(t)=b_{i}^{k+1} \lambda_{i, 0}\left(t+a_{i} \sum_{\eta=0}^{k} T_{\eta}\right)
$$

Where:

$\lambda_{i, 0}$ - the initial failure rate of the machine tool.

The corrective maintenance times of the i-th module in the $\mathrm{k}$-th preventive maintenance cycle can be obtained according to formula (13):

$$
h_{i, k}=\int_{0}^{T_{k}} \lambda_{i, k}(t) d t=\int_{0}^{T_{k}}\left(t+a_{i} \sum_{\eta=0}^{k-1} T_{\eta}\right)
$$




$$
=\frac{b_{i, k}}{\mu_{i} m_{i}}\left[\left(T_{k}+a_{i} \sum_{\eta=0}^{k-1} T_{\eta}\right)^{m_{i}}-\left(a_{i} \sum_{\eta=0}^{k-1} T_{\eta}\right)^{m_{i}}\right]
$$

System reliability from the perspective of the module, the reliability of the machine tool can be calculated by the reliability of the key modules. The reliability and failure rate of the modules are shown below:

$$
R_{i}(t)=e^{-\int_{0}^{t} \lambda_{i}(t) d t}
$$

The reliability function of the $\mathrm{i}$-th module after preventive maintenance can be obtained according to the recurrence law of the failure rate function:

$$
R_{i, k}=e^{-h_{i, k}}
$$

The comprehensive reliability of each module of rotary ultrasonic vibration-assisted EDM can be expressed as the reliability function of the machine tool. The reliability formula after $\mathrm{k}$-th preventive maintenance activities is as follows:

$$
R_{k}(t)=f\left(R_{1, k}(t), R_{2, k}(t), \ldots R_{n, k}(t)\right)
$$

Taking the minimum reliability of the system as the constraint and reducing the cost as much as possible as the goal, the objective function is $\operatorname{Minc}_{\text {total }}(\mathrm{N}, \mathrm{T}), \mathrm{N}$ and $\mathrm{T}=$ $\left\{T_{0}, T_{1} \ldots T_{k}, \ldots T_{N}\right\}$ Is a decision variable, and the constraint function is:

Where:

$$
\begin{aligned}
& R_{k} \geq R_{\min } \\
& \sum_{k=1}^{N} t_{k}+\sum_{k=0}^{N} T_{k}=L
\end{aligned}
$$

$t_{k}$ - Time spent on preventive maintenance activities during $\mathrm{K}$.

The cost optimization analysis of the five modules of the rotary ultrasonic vibrationassisted EDM machine tool servo control system, $\mathrm{X}-\mathrm{Y}$ motion system, Z-axis motion system, spindle rotation system and ultrasonic vibration system is determined by establishing a mathematical model of total cost and reliability analysis.

The lifetime of the rotary ultrasonic vibration-assisted EDM machine tool is 10 years ( 87,600 hours), the reliability constraint is 0.875 , the preventive maintenance cost is 500, and other parameters are shown in Table.4.

Table.4 The parameters of each module of the rotary ultrasonic vibration-assisted EDM machine tool

\begin{tabular}{lccccccc}
\hline & $h_{\text {itotal }}$ & $b_{i, k}$ & $a_{i, k}$ & $m_{i}$ & $\mu_{i}$ & $c_{i}$ & $t_{k}$ \\
\hline Servo control & 1.55629 & 1.1 & 0.2 & 3 & 8 & 2000 & 0.00667 \\
X-Y-axis & 1.10143 & 1.1 & 0.2 & 2 & 7 & 2000 & 0.00667 \\
Z-axis & 1.70447 & 1.1 & 0.2 & 2 & 7 & 1500 & 0.00667 \\
Spindle rotation & 1.25989 & 1.2 & 0.2 & 3 & 7 & 2500 & 0.00667 \\
Ultrasonic vibration & 1.44531 & 1.2 & 0.2 & 3 & 7 & 2500 & 0.00667 \\
\hline
\end{tabular}

As shown in Table.4, the failure time for each module of the rotary ultrasonic vibration-assisted EDM machine tool within 10 years is determined by the failure rate of each module when $\alpha=0.7$ in Table 3. Substituting the parameters in Table. 4 into formulas (14) and (16), the reliability of each module after the k-th preventive maintenance can be obtained:

$$
R_{1, k}(t)=e^{\left\{-\frac{1.1^{k}}{8^{3}}\left[\left(T_{k}+0.2 \sum_{\eta=0}^{k-1} T_{\eta}\right)^{3}-\left(0.2 \sum_{\eta=0}^{k-1} T_{\eta}\right)^{3}\right]\right\}}
$$




$$
\begin{aligned}
& R_{2, k}(t)=R_{3, k}(t)=e^{\left\{-\frac{1.1^{k}}{6^{3}}\left[\left(T_{k}+0.2 \sum_{\eta=0}^{k-1} T_{\eta}\right)^{3}-\left(0.2 \sum_{\eta=0}^{k-1} T_{\eta}\right)^{3}\right]\right\}} \\
& R_{4, k}(t)=R_{5, k}(t)=e^{\left\{-\frac{1.2^{k}}{7^{3}}\left[\left(T_{k}+0.2 \sum_{\eta=0}^{k-1} T_{\eta}\right)^{3}-\left(0.2 \sum_{\eta=0}^{k-1} T_{\eta}\right)^{3}\right]\right\}}
\end{aligned}
$$

The series-parallel structure of the 5 modules of the rotary ultrasonic vibrationassisted EDM machine tool is shown in Fig.4:

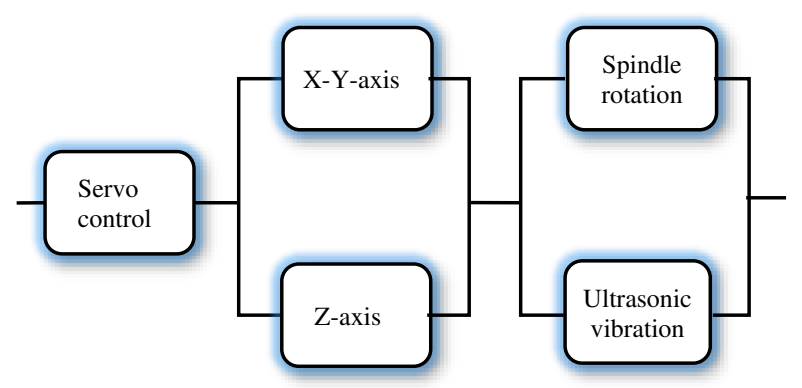

Fig.4 Series-parallel structure between modules of rotary ultrasonic vibration-assisted EDM machine tool

The reliability of the rotary ultrasonic vibration-assisted EDM machine tool is determined by the series-parallel relationship of each module. According to formula (17):

$$
\begin{aligned}
R_{k}(t)= & \left(R_{2, k}(t)+R_{3, k}(t)-R_{2, k}(t) R_{3, k}(t)\right) \times\left(R_{4, k}(t)+R_{5, k}(t)-\right. \\
& \left.R_{4, k}(t) R_{5, k}(t)\right) \times R_{1, k}(t)
\end{aligned}
$$

\subsection{Optimal maintenance times of rotary ultrasonic vibration-assisted EDM}

As shown in Table.5, given the maintenance times $(\mathrm{N})$ and the total cost $c_{\text {total }}(N, T)$

\begin{tabular}{lrr}
\multicolumn{3}{c}{ Table.5 Maintenance times, total cost, average system reliability } \\
\hline $\mathrm{N}$ & $c_{\text {total }}(N, T)$ & $R_{\text {AVER }}$ \\
\hline 3 & 16135.145 & 0.8650 \\
4 & 16635.145 & 0.9125 \\
5 & 17135.145 & 0.9376 \\
6 & 17635.145 & 0.9523 \\
7 & 18135.145 & 0.9615 \\
8 & 18635.145 & 0.9676 \\
9 & 19135.145 & 0.9717 \\
10 & 19635.145 & 0.9748 \\
11 & 20135.145 & 0.9774 \\
12 & 20635.145 & 0.9778 \\
13 & 21135.145 & 0.9783 \\
\hline
\end{tabular}


and the average system reliability calculated according to formula (10), Obtaining the best maintenance time can be based on the relationship between average system reliability and cost, while ensuring the lowest reliability.



Fig.5 The relationship between average system reliability and cost

\subsection{Reliability of rotary ultrasonic vibration-assisted EDM under fixed maintenance intervals and non-fixed maintenance intervals}

As shown in Fig.5: When $\mathrm{N}$ is set to 3, the average reliability of the system is close to 0.875 and the maintenance cost is too high, its cost performance is very low. In order to ensure that the rotary ultrasonic vibration-assisted EDM machine tool $R_{i, k}$ is greater than 0,875 . Taking $\mathrm{N}$ as 5 , calculate the $R_{i, k}$ of the fixed and non-fixed maintenance period of the rotary ultrasonic vibration-assisted EDM machine tool according to formulas (19)-(20). (Table.6 and table.7).

Table.6 $R_{i, k}$ under a fixed maintenance period

\begin{tabular}{ccc}
\hline$k$ & $T_{k}$ & $R_{i, k}$ \\
\hline 1 & 1.662 & $98.96 \%$ \\
2 & 1.662 & $97.86 \%$ \\
3 & 1.662 & $95.99 \%$ \\
4 & 1.662 & $92.84 \%$ \\
5 & 1.662 & $87.96 \%$ \\
6 & 1.662 & $79.63 \%$ \\
\hline \multicolumn{2}{l}{ Table.7 $R_{i, k}$ under a non-fixed maintenance period } \\
\hline$k$ & $T_{k}$ & $R_{i, k}$ \\
\hline 1 & 2.185 & $97.39 \%$ \\
2 & 1.975 & $95.79 \%$ \\
3 & 1.785 & $93.94 \%$ \\
4 & 1.565 & $92.09 \%$ \\
5 & 1.335 & $90.07 \%$ \\
6 & 1.125 & $89.62 \%$ \\
\hline
\end{tabular}

The reliability comparison of the rotary ultrasonic vibration-assisted EDM machine tool after the $\mathrm{i}$-th maintenance under the fixed and the non-fixed maintenance cycle is shown in Fig.6. 


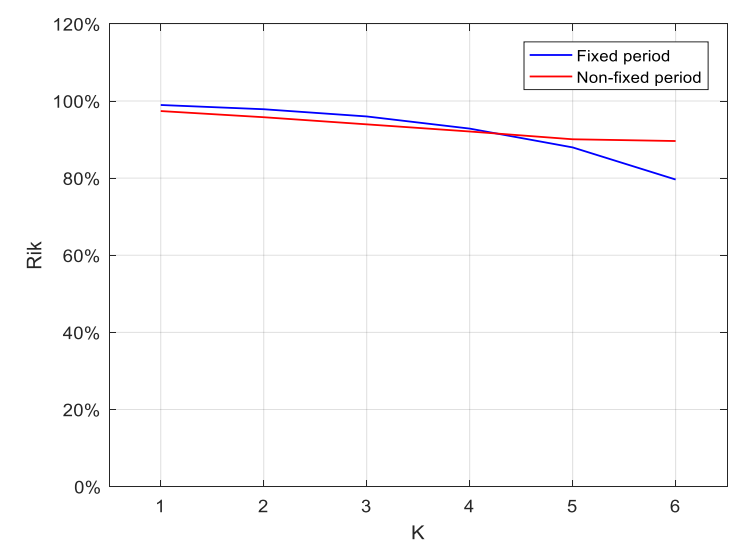

Fig. 6 Comparison of $R_{i, k}$ under fixed maintenance period and non-fixed maintenance period

As shown in Fig.6, as the number of maintenance increases, the reliability of rotary ultrasonic vibration-assisted EDM machine tools declines rapidly within a fixed maintenance period. Its reliability no longer meets the requirements after the fifth maintenance. as the number of maintenance increases, the reliability of rotary ultrasonic vibration-assisted EDM machine tools slowly declines within a fixed maintenance period. Its reliability still meets the requirements after the fifth maintenance.

\subsection{Total maintenance cost of rotary ultrasonic vibration-assisted EDM machine tools under different measure}

Cost optimization can be achieved by varying the different measures determined at the time the maintenance times and reliability premise. When $\alpha=0.7$, the total maintenance cost of the rotary ultrasonic vibration-assisted EDM machine tool is $17135.145 \mathrm{RMB}$, and when $\alpha$ is taken 0.5 , the total maintenance cost of the rotary ultrasonic vibrationassisted EDM machine tool is 15306.07 RMB, a reduction of 1829.075 RMB.

\section{Conclusions}

The maximum entropy ordered weighted average algorithm was used to accurately predict the failure rate of each module of the rotary ultrasonic vibration-assisted EDM machine tool. And the corrective maintenance cost of each module was determined by this algorithm and combined with the preventive maintenance cost to establish a cost model. This method was applied to rotary ultrasonic vibration assisted EDM machine tools (as shown in Figure 3), it was predicted that the machine tool could be subjected to preventive maintenance 5 times in a non-fixed maintenance cycle within 10 years. The results showed that the preventive maintenance cost of $2500 \mathrm{RMB}$ can be determined by determining the optimal maintenance times of the rotary ultrasonic vibration-assisted EDM machine tool. The reliability of rotary ultrasonic vibrationassisted EDM machine tools was reduced $19.33 \%$ through 5 preventive maintenance in a fixed maintenance cycle, the reliability of rotary ultrasonic vibration-assisted EDM machine tool was reduced $7.77 \%$ through 5 preventive maintenance in a non-fixed maintenance cycle, it was verified that the reliability of the machine tool can be 
improved by changing the maintenance interval. Corrective maintenance costs were reduced $10.67 \%$ through change measures on the premise of determining the best maintenance time and reliability. Therefore, the reliability and cost optimization of rotary ultrasonic vibration-assisted EDM machine tool can be achieved through the algorithm of maximum entropy ordered weighted average combined with total cost index.

\section{Author contribution}

Minggang Xu and Hao Fu: validation, analysis, investigation,writing of the original draft. Wang Tian and Binbin lyu: Data calculation, analysis, investigation, writing review. Zihao Jiang and Baosheng Guan: investigation, analysis, writing review.

Availability of data and materials The datasets used or analyzed during the current studyare available from the corresponding author on reasonable request.

Code availability Not applicable

Funding National Natural Science Foundation of China (51205005)

\section{Declarations}

Ethics approval This paper is our original unpublished work, and it has not been submitted to any other journal for reviews.

Consent to participate All authors were fully involved in the study and preparation of the manuscript; each of the authors has read and concurs with the content in the final manuscript.

Consent for publication All authors consent to publish the content in the final manuscript.

Competing interests The authors declare no competing interests.

\section{References}

1. Maity K P, Choubey M. A review on vibration-assisted EDM, micro-EDM and WEDM [J]. Surface Review and Letters, 2019, 26(05): 1830008.https://doi.org/10.1142/S0218625 $\mathrm{X} 18300083$

2. Sabyrov N, Jahan M P, Bilal A, et al. Ultrasonic vibration assisted electro-discharge mac hining (edm)-An overview[J]. Materials, 2019, 12(3): 522.https://doi.org/10.3390/ma120 30522

3. Tsai M Y, Fang C S, Yen M H. Vibration-assisted electrical discharge machining of groo ves in a titanium alloy (Ti-6A-4V) [J]. The International Journal of Advanced Manufactu ring Technology, 2018, 97(1): 297-304. https://doi.org/10.1007/s00170-018-1904-2

4. Yinghuai D, Jianbao S, Guangyan L, et al. Research on non-contact ultrasonic vibration assisted rotating electrical discharge machining (EDM) machine tool[J]. International Jour nal of Nanomanufacturing, 2021, 17(1): 1-12.https://doi.org/10.1504/IJNM.2021.113298

5. Wang Y, Liu Z, Shi J, et al. Analysis of material removal and surface generation mecha nism of ultrasonic vibration-assisted EDM[J]. The International Journal of Advanced Ma nufacturing Technology, 2020, 110(1):177-189. https://doi.org/10.1007/s00170-020-05769- 
6. Hirao A, Gotoh H, Tani T. Some Effects on EDM Characteristics by Assisted Ultrasonic Vibration of the Tool Electrode[J]. Procedia CIRP, 2018,68:76-80. https://doi.org/10.1016 /j.procir.2017.12.025

7. Kumar S, Grover S, Walia R S. Analyzing and modeling the performance index of ultras onic vibration assisted EDM using graph theory and matrix approach[J]. International Jo urnal on Interactive Design and Manufacturing (IJIDeM), 2018,12(1):225-242. https://doi. org/10.1007/s12008-016-0355-y

8. Lin Y C, Chuang F P, Wang A C, et al. Machining characteristics of hybrid EDM with ultrasonic vibration and assisted magnetic force[J]. International journal of precision engi neering and manufacturing, 2014, 15(6): 1143-1149.https://doi.org/10.1007/s12541-014-04 49-z

9. Shervani-Tabar M T, Maghsoudi K, Shabgard M R. Effects of simultaneous ultrasonic vi bration of the tool and the workpiece in ultrasonic assisted EDM[J]. International Journal for Computational Methods in Engineering Science and Mechanics, 2013,14(1):1-9. http s://doi.org/10.1080/15502287.2012.698696

10. Teimouri R, Baseri H. Experimental study of rotary magnetic field-assisted dry EDM wit $\mathrm{h}$ ultrasonic vibration of workpiece[J]. The International Journal of Advanced Manufactur ing Technology, 2013, 67(5-8):1371-1384. https://doi.org/10.1007/s00170-012-4573-6

11. Cheng Q, Wang H, Liu Z, et al. Reliability allocation method based on maximum entrop y ordered weighted average and hesitant fuzzy Linguistic term set[J]. Journal of Intellige nt \& Fuzzy Systems, 2019, 37(6):7991-8004. https://doi.org/10.3233/JIFS-190376

12. Maldonado S, Merigó J, Miranda J. Redefining support vector machines with the ordere d weighted average[J]. Knowledge-Based Systems, 2018, 148:41-46. https://doi.org/10.10 16/j.knosys.2018.02.025

13. Chaji A. Analytic approach on maximum Bayesian entropy ordered weighted averaging operators[J]. Computers \& Industrial Engineering, 2017,105:260-264. https://doi.org/10.10 16/j.cie.2016.12.041

14. Kabir G, Tesfamariam S, Loeppky J, et al. Integrating Bayesian linear regression with or dered weighted averaging: Uncertainty analysis for predicting water main failures[J]. AS CE-ASME Journal of Risk and Uncertainty in Engineering Systems, Part A: Civil Engin eering, 2015, 1(3): 04015007. https://doi.org/10.1061/AJRUA6.0000820

15. Yari G, Chaji A R. Maximum Bayesian entropy method for determining ordered weighte d averaging operator weights[J]. Computers \& Industrial Engineering, 2012,63(1):338-34 2. https://doi.org/10.1016/j.cie.2012.03.010

16. Ahn B S. Compatible weighting method with rank order centroid: Maximum entropy ord ered weighted averaging approach[J]. European Journal of Operational Research, 2011,21 2(3):552-559. https://doi.org/10.1016/j.ejor.2011.02.017

17. Treanţă S. On a Class of Constrained Interval-Valued Optimization Problems Governed b y Mechanical Work Cost Functionals[J]. Journal of Optimization Theory and Application s, 2021, 188(3): 913-924. https://doi.org/10.1007/s10957-021-01815-0

18. Xiao H, Zhang R, Chen Z, et al. Maintenance cycle optimisation of multi-component sys tems under the constraints of overall cost and reliability[J]. International Journal of Emb edded Systems, 2020, 13(2): 148-157. https://doi.org/10.1504/IJES.2020.108862 
19. Liu J, Chen Q, Liang X, et al. Manufacturing cost constrained topology optimization for additive manufacturing[J]. Frontiers of Mechanical Engineering, 2019, 14(2):213-221. htt ps://doi.org/10.1007/s11465-019-0536-z

20. Klanšek U. Cost optimization of project schedules under constrained resources and altern ative production processes by mixed-integer nonlinear programming[J]. Engineering, Con struction and Architectural Management, 2019. https://doi.org/10.1108/ECAM-01-2019-00 13

21. Domínguez-Isidro S, Mezura-Montes E. A cost-benefit local search coordination in multi meme differential evolution for constrained numerical optimization problems[J]. Swarm a nd evolutionary computation, 2018, 39: 249-266. https://doi.org/10.1016/j.swevo.2017.10. 006

22. O'Hagan M. Aggregating template or rule antecedents in real-time expert systems with $f$ uzzy set logic[C]//Twenty-second Asilomar conference on signals, systems and computer s. IEEE, 1988, 2: 681-689. https://doi.org/10.1109/ACSSC.1988.754637

23. Fullér R, Majlender P. An analytic approach for obtaining maximal entropy OWA operat or weights[J]. Fuzzy sets and Systems, 2001, 124(1):53-57. https://doi.org/10.1016/S01650114(01)00007-0

24. Guo S, Sun Y, Zhao G, et al. Optimization of maintenance strategy for multi-component system subject to degradation process[C]/2016 Prognostics and System Health Managem ent Conference (PHM-Chengdu). IEEE, 2016: 1-6. https://doi.org/10.1109/PHM.2016.781 9854 
Figures

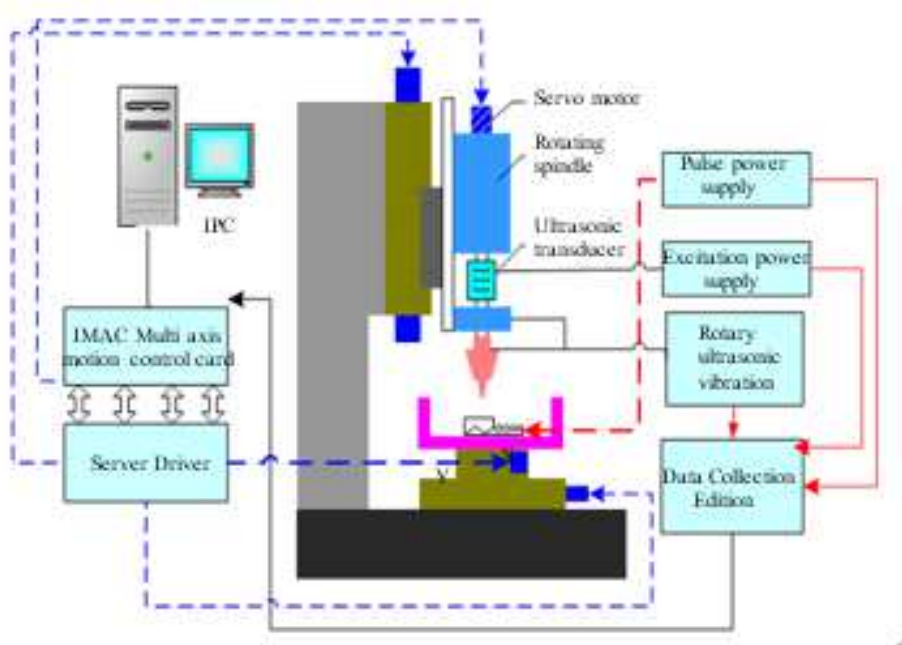

Figure 1

Schematic diagram of the control system of the rotary ultrasonic vibration-assisted EDM machine tool

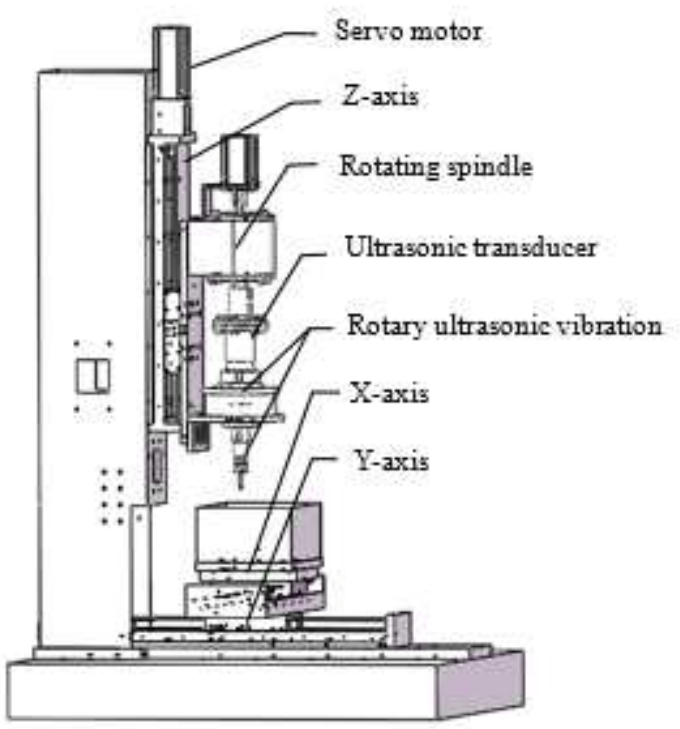

Figure 2

3D modeling of rotary ultrasonic vibration-assisted EDM machine tool 


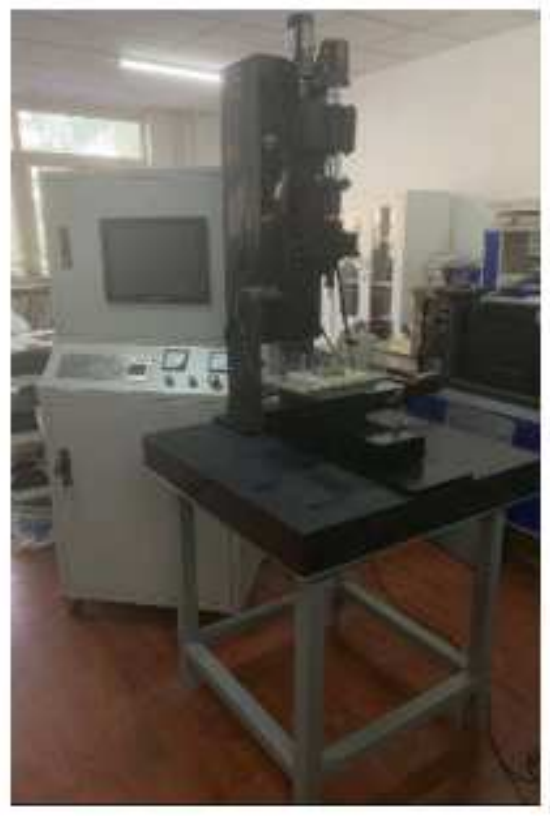

Figure 3

Rotary ultrasonic vibration-assisted EDM machine tool

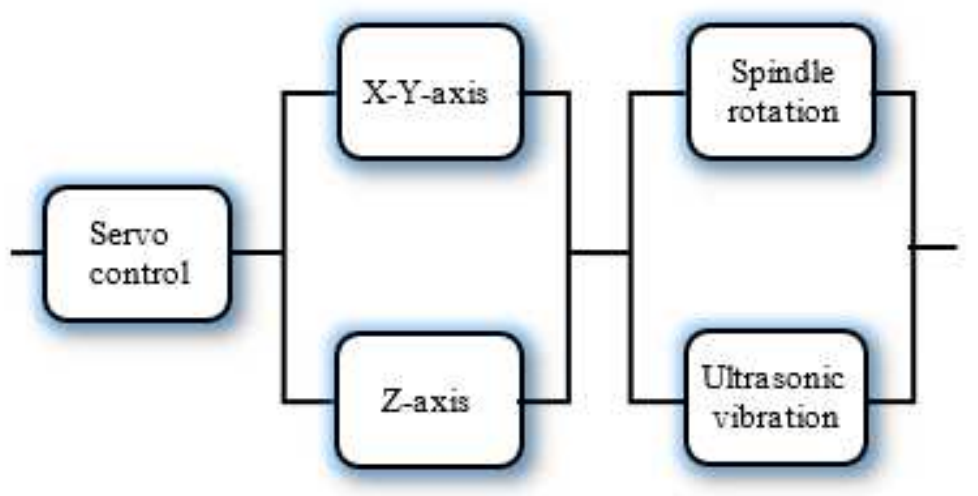

Figure 4

Series-parallel structure between modules of rotary ultrasonic vibration-assisted EDM machine tool 


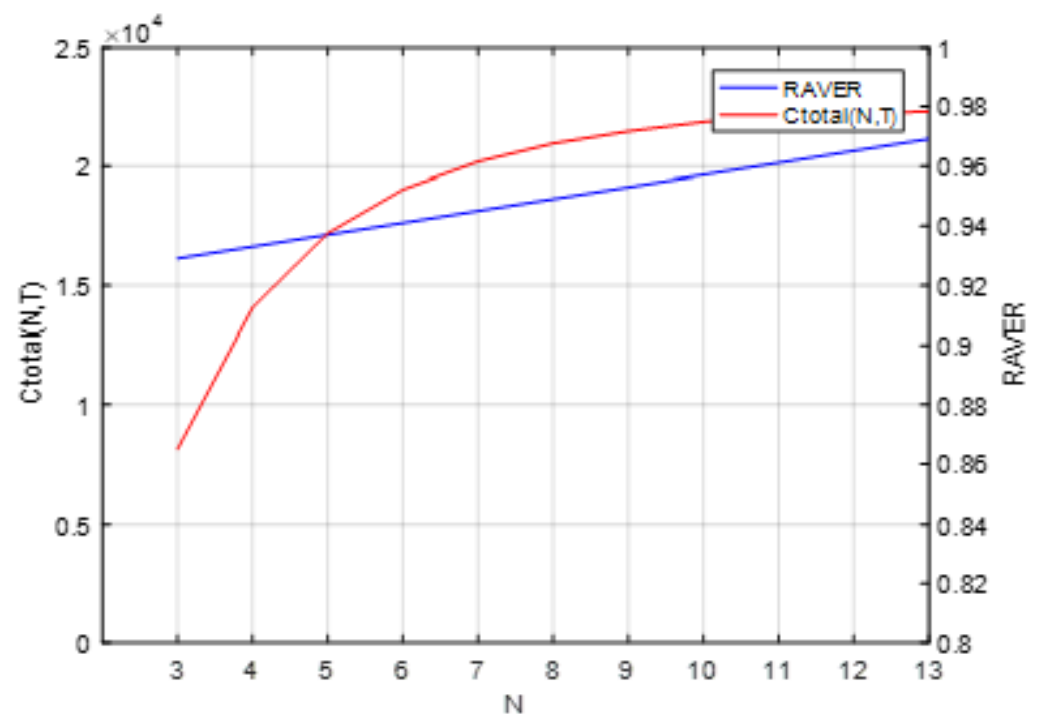

\section{Figure 5}

The relationship between average system reliability and cost

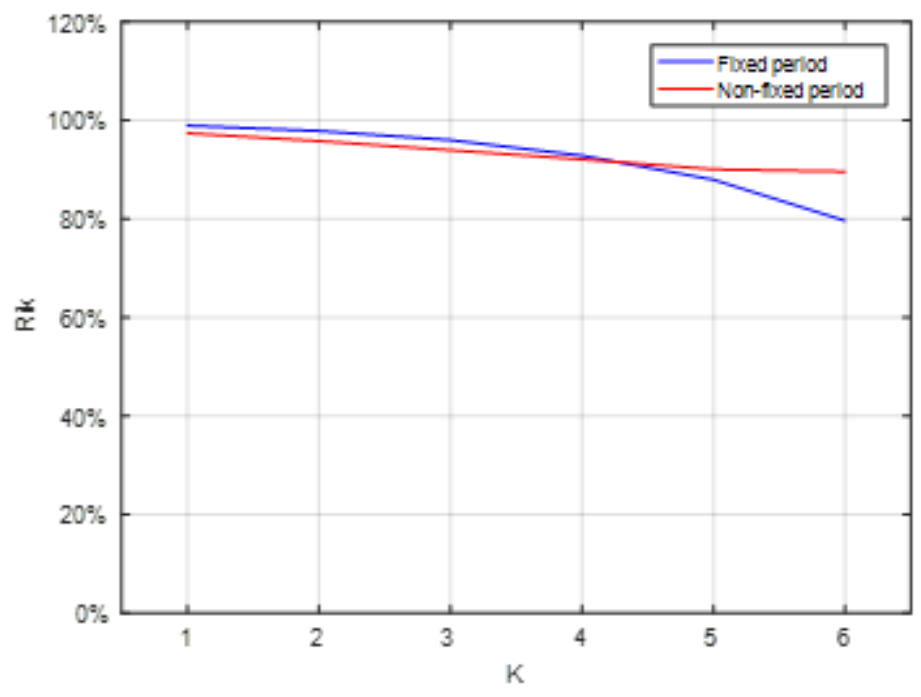

Figure 6

Comparison of $\mathrm{R}(\mathrm{i}, \mathrm{k})$ under fixed maintenance period and non-fixed maintenance period 